\title{
ДИАБЕТИЧЕСКАЯ НЕЙРОПАТИЯ У ДЕТЕЙ: СЛОЖНОСТИ ДИАГНОСТИКИ И ТАКТИКИ ВЕДЕНИЯ
}

\author{
'Макина О.В., ${ }^{\top}$ Туз В.В., 'Петрова Н.А., 'Ларина Е.А., Батяева М.М. \\ 'ФГБОУ ВО «Ярославский государственный медицинский университет Минздрава России», Ярославль \\ гГБУз яО «Областная детская клиническая больница», Ярославль
}

\begin{abstract}
АКТУАЛЬНОСТЬ: диабетическая полинейропатия (ДПН) — наиболее раннее и частое осложнение сахарного диабета 1 типа, которое оказывает существенное влияние на трудоспособность и социальную активность больных [4]. ДПН развивается на фоне хронической гипергликемии и ассоциирована с патологическими метаболическими изменениями (активация полиолового пути, накопление конечных продуктов гликирования, оксидативный стресс, дислипидемия).

Впервые проведена комплексная оценка состояния периферической и вегетативной нервной системы у детей с СД1 для диагностики ДПН.

ЦЕЛЬ: изучение частоты встречаемости, структуры и факторов риска ДПН у детей и подростков Ярославской области.

МАТЕРИАЛЫ И МЕТОДЫ: обследовано 44 ребенка с СД1 в возрасте 5-17 лет. Диагностика ДПН проводилась с помощью шкал для скрининга и оценки выраженности симптомов диабетической нейропатии: Мичиганского опросника для скрининга нейропатии, шкалы неврологических симптомов, оценки вибрационной чувствительности, тактильной и болевой стандартными методиками. Статистическая обработка оценивалась методом проверки гипотез о равенстве средних значений двух выборок с помощью коэффициента Стьюдента.
\end{abstract}

РЕЗУЛЬТАТЫ И ОБСУЖДЕНИЕ: ПрИ НевроЛогИческом осмОтре У $31,8 \%$ детей отмечено СниЖенИе вИбрационной чувствительности, у 20,5\% тактильной. Снижения температурной и болевой чувствительности, нарушения суставно-мышечного чувства выявлено не было. Клинические признаки были оценены нами по совокупности жалоб, их длительности, прогрессирования симптоматики с течением заболевания, а также исходя из снижения чувствительности и рефлексов нижних конечностей. Диагноз ДПН был выставлен 41\% пациентам. Корреляционный анализ показал достоверную связь наличия ДПН с длительностью диабета $(p<0,0005)$, уровнем $\mathrm{HbA1c}(p<0,05)$. Взаимосвязи с возрастом пациентов, показателями липидного спектра в нашей выборке оказались статистически незначимыми. Диагностика кардиоваскулярной формы проводилась по результатам сбора жалоб пациентов: на приступы сердцебиения без особого напряжения - 9,1\%, на головокружение - 20,5\%, на головокружение при резкой смене положения тела - 15,9\%. Жалобы гастроинтестинального характера на боли в животе предъявляли $18,2 \%$ пациентов, на ощущение переполнения желудка $-27,3 \%$, на тяжесть и боль в правом подреберье - 6,8\%, на тошноту - 11,4\%. Подобные жалобы неспецифичны, но данный факт ставит вопрос о включении таких пациентов в группу риска по гастроинтестинальной нейропатии. Диагностически значимым исследованием мочеполовой нейропатии является урофлоуметрия. С помощью данного метода возможно своевременно определить начальную стадию нарушений мочеиспускания при СД и предотвратить их дальнейшее развитие.

ВЫВОды: частота встречаемости ДПН составила 41\% с преобладанием начальных клинических форм; достоверными факторами риска развития ДПН является длительность заболевания 4 года и более, декомпенсированные показатели $\mathrm{HbA1c;}$ нарушение вибрационной чувствительности выявлено у $31,8 \%$; пациентов со специфическими жалобами или симптомами необходимо определить в группы риска по формированию диабетической автономной нейропатии. 